\title{
Development of an information and analytical model of soils based on X-ray fluorescence analysis
}

\author{
E.M. Basarygina, N.A. Pakhomova*, and O.E. Akulich \\ Federal State Budgetary Educational Institution of Higer Educaton South Ural StatecAgrarian \\ University Chelyabinsk, Russia
}

\begin{abstract}
The purpose of the research was to build information and analytical models of the soil based on the data of energy-dispersive X-ray fluorescence analysis. For the soil of the Chelyabinsk region, on the basis of experimental data, information and analytical models are constructed, showing a complete list of chemical elements and trace elements, the content of which exceeds the permissible concentration. These models, which clearly reflect the content of micro-and macronutrients in the soil, are recommended for use in the development of measures for soil reclamation and the involvement of fallow lands in agricultural turnover.
\end{abstract}

\section{Introduction}

Information and analytical models that describe the main properties of an object and are built on the basis of analysis can be presented in the form of tables, diagrams, diagrams, diagrams, graphs, etc.).

These models allow you to systematize and structure the source information, which makes it easier to work with a large amount of data [4], [9]. Structured data related, in particular, to the chemical analysis of soils, can be used in the development of measures for the reclamation of soils and the introduction of fallow lands into circulation.

Purpose: to build an information and analytical model of soils based on X-ray fluorescence analysis.

\section{Tasks:}

1. X-ray fluorescence analysis of the soil (on the example of the Chelyabinsk region).

2. Construction of an information and analytical model of the soil based on the obtained data for a complete list of macro-and microelements.

3. Building an information and analytical model for trace elements whose content exceeds the permissible concentration.

\footnotetext{
* Corresponding author: natali-pakhomova@mail.ru
} 


\section{Materials and methods}

The current problem of land resources is associated with soil degradation, primarily due to anthropogenic impact [3], [5]. Possible forms of environmental pollution [1], [2] are shown in Figure 1.

The main objects of pollution are the following components of the ecotone: soil, water, atmosphere; indirect objects of pollution are those that leave agrobiogeocenoses: plants, animals, people.

At the same time, currently up to $50 \%$ of the arable land area is not involved in agricultural turnover (data from the Agrarian Committee of the State Duma of the Russian Federation). The problem of involving fallow lands in agricultural turnover is also relevant for the Chelyabinsk region, where deposits account for more than $40 \%$. Effective recultivation of deposits will facilitate the natural restoration of natural ecosystems, the return of land to the original use of natural resources [6].

The main data used in the development of measures for the restoration of soils and their introduction into agricultural circulation is the gross content of macro-and microelements. 


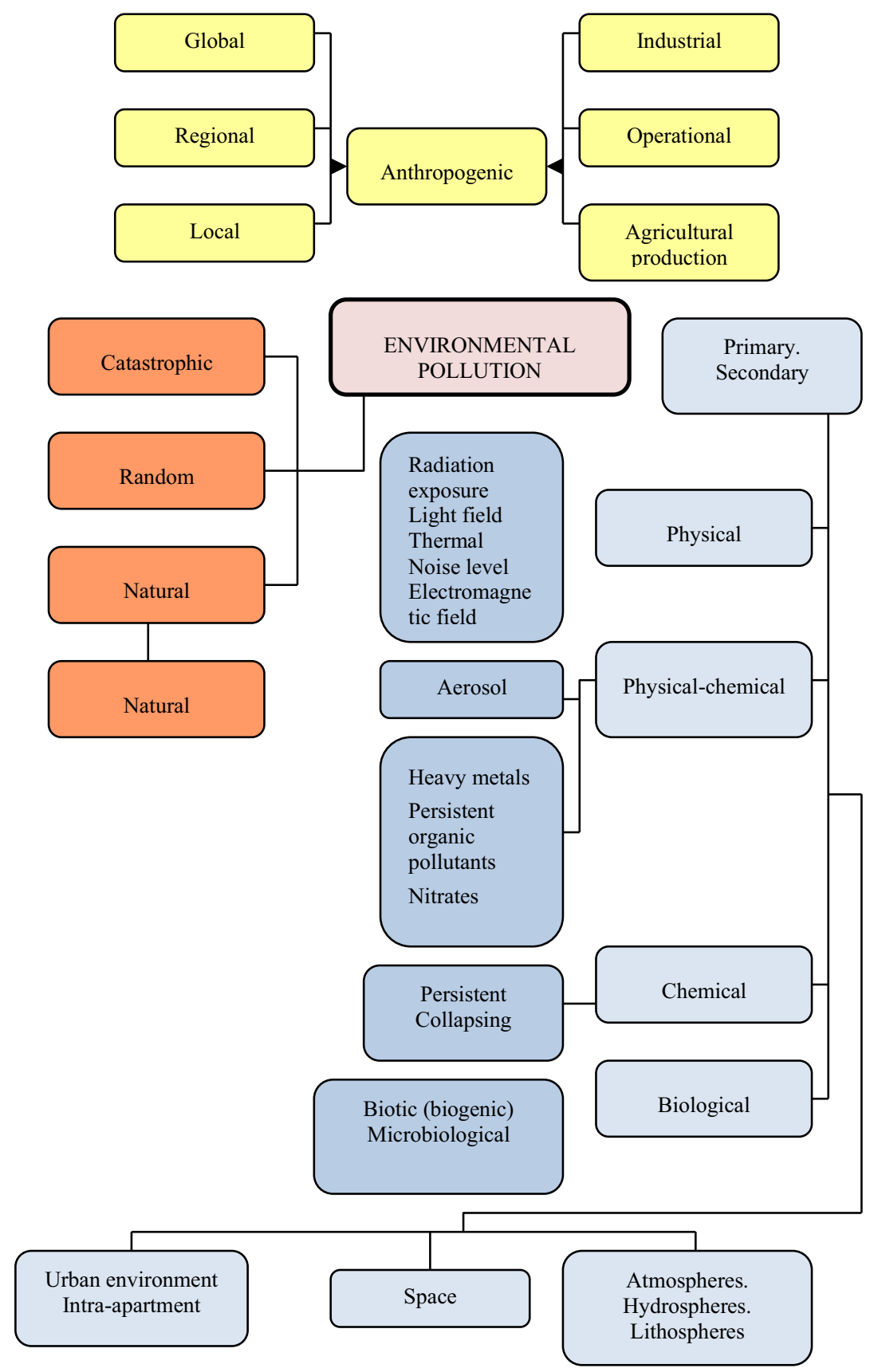

Fig. 1. Forms of environmental pollution.

To analyze the soils of the Chelyabinsk region, an X-ray fluorescence method was used, which allows obtaining operational information about the content of chemical elements in the soil. 
Energy-dispersive X-ray fluorescence analysis is widely used in the work of research organizations and laboratories, since it has advantages over the known methods according to the following criteria: the number of elements to be determined, the concentration of elements, the accuracy of the results, the complexity of the analysis and preparation, the duration of each test [7].

Equipment: A Rayny EDX-720 Shimadzu spectrometer was used to perform the soil analysis. Among the features of the device are: a semiconductor detector, an X-ray tube with a rhodium anode; a vacuum system; liquid nitrogen cooling; a video camera for viewing the test sample; a turret for flow analysis; spectrum registration on the Na-Sc, Ti-U channels [10]. When processing the results of the experiment, well-known methods of statistical analysis were used [8].

\section{Results of the study}

To solve the first problem, an information and analytical model for the soil of the Chelyabinsk region is constructed on the basis of X-ray fluorescence analysis data (Fig. 2). The content of elements is given in $\mathrm{g} / \mathrm{kg}$.

The developed model allows you to visually display the chemical composition of the soil and identify elements whose content exceeds the permissible concentration. Such elements (shown in red) include zinc, copper, and lead.

For these elements, in accordance with the second task, a model is constructed that displays the gross content and maximum permissible concentration (MPC). The author's program used in the construction of the model quickly reflects all deviations on the diagram (Fig. 3).

The information and analytical models shown in Figures 2-3 are recommended for use in the development of measures for land reclamation and their involvement in agricultural turnover. 
$=\mathrm{Si}=\mathrm{Ca}=\mathrm{Ti}=\mathrm{S}=\mathrm{K}=\mathrm{Sr}=\mathrm{Fe}=\mathrm{Cu}=\mathrm{Cr}=\mathrm{Br}$

$\|\mathrm{Mn}\| \mathrm{V}\|\mathrm{Ni}\| \mathrm{Zn}\|\mathrm{Mg}\| \mathrm{P}\|\mathrm{Mo}\| \mathrm{Se}\|\mathrm{Sb}\| \mathrm{Hg}$

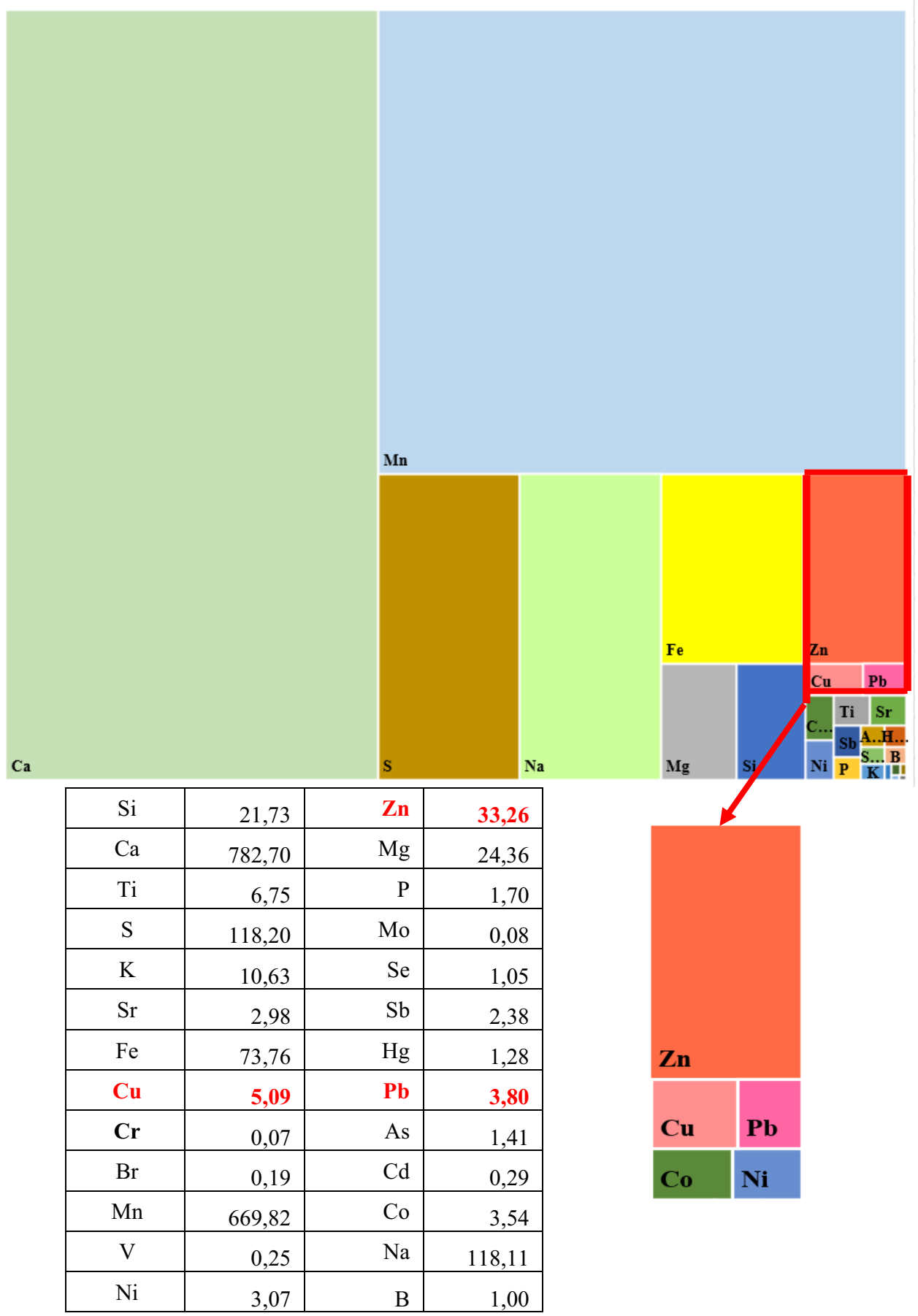

Fig.2. Information and analytical model of the soil. 
The analysis of the data shown in Figure 3 allows us to establish that the excess of the MPC is: for copper - 70\%; for zinc-58\%; for lead- $80 \%$.

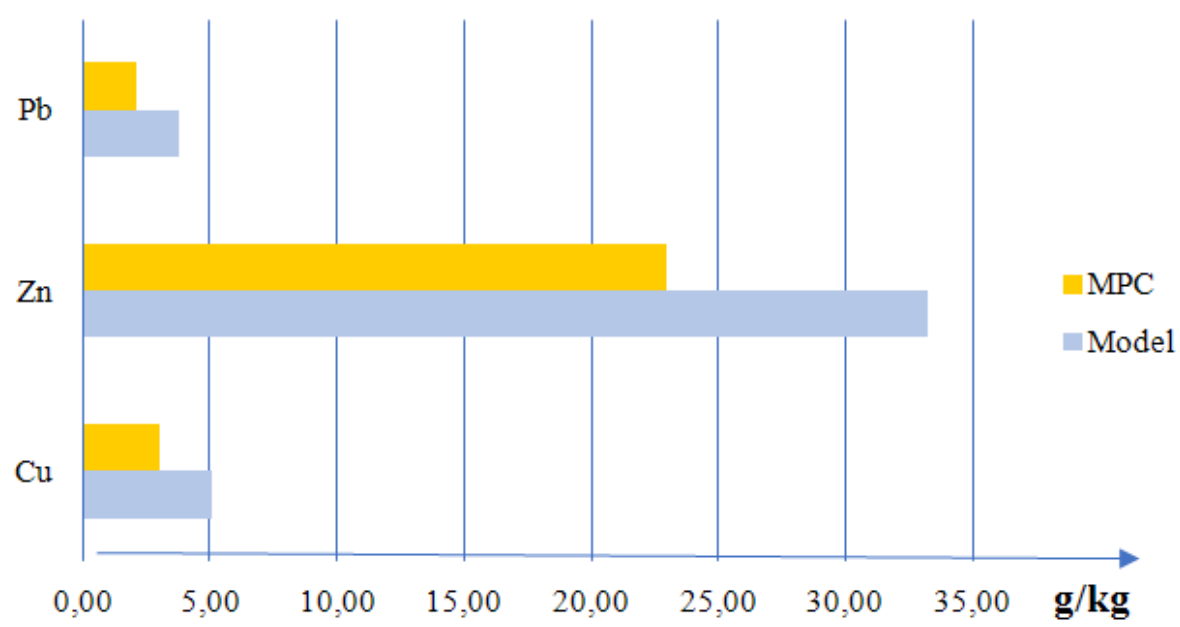

Fig. 3. Information and analytical model of the soil for trace elements whose content exceeds the maximum permissible concentration.

Important information when choosing such measures is the data on the content of trace elements, in particular, copper, cobalt, molybdenum, zinc, boron. The comparison of the data on the content of these elements with the optimal (insufficient / excessive) content is shown in Figure 4.

The analysis of the presented data allows us to conclude that the content of copper, zinc, and cobalt is excessive (exceeds the upper limit), the content of boron is optimal (located between the upper and lower limits), and the content of molybdenum is insufficient (less than the lower limit).

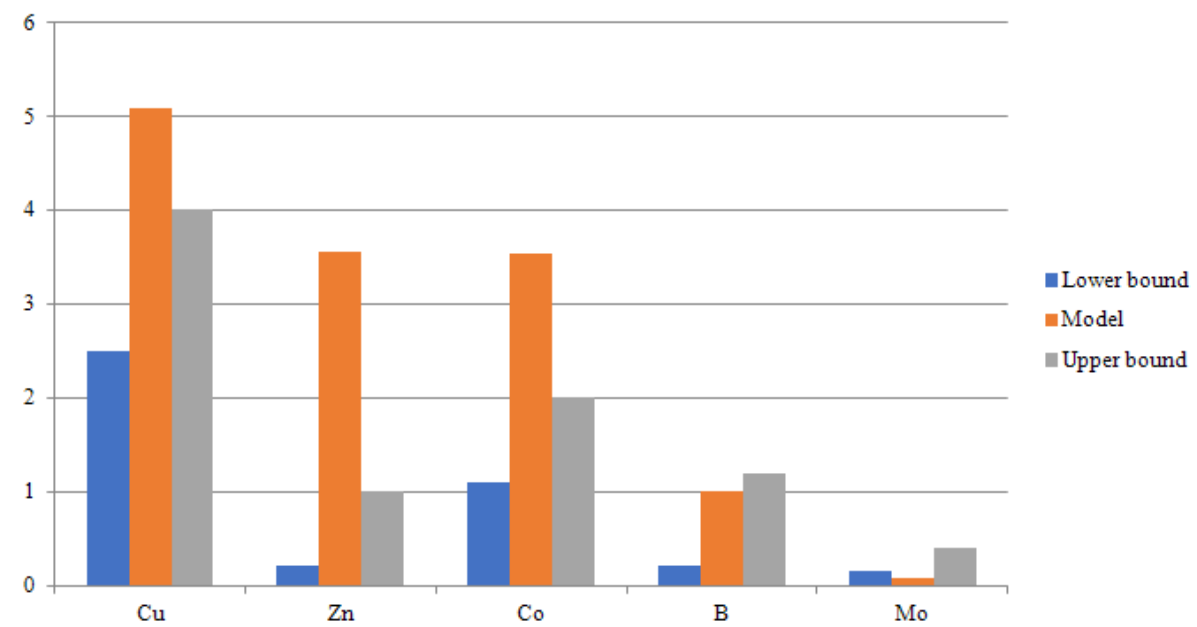

Fig. 4. Comparison of the established content of trace elements with the optimal content. 
Thus, as a result of the conducted theoretical and experimental studies, information and analytical models of the soil were constructed (on the example of the Chelyabinsk region). These models, which clearly reflect the content of micro-and macronutrients in the soil, are recommended for use in the development of measures for soil reclamation and the involvement of fallow lands in agricultural turnover.

\section{References}

1. Analysis of Trace Elements in Water using Ultra Thin Film, Rayny EDX-700/800. Application Data, 12 - 17 (2008 - 2009)

2. Cecilia M.G. Onesimo, Diego D. Dias, Marina Vale Beirao, Restoration Ecology (2021)

3. G.R. Puno, R.A. Marin, R.C.C. Puno, Global journal of environmental science and management-gjesm (2021)

4. N.V. Elizarov, V.V.Popov, N.V. Semendyaeva, Eurasian soil science (2020)

5. Dos Santos Teixeira, Anita Fernanda, Godinho Silva, Sergio Henrique, de Carvalho, Teotonio Soares, Soil physicochemical properties and terrain information predict oil enzymes activity in phytophysiognomies of the Quadrilatero Ferrifero region in Brazil (2021)

6. O.D. Rubaeva, I.A. Zubareva, N.A. Pakhomova, E.A. Malykhina, J ournal of Environmental Management and Tourism, http://www.asers.eu/asers-publishing ISSN 2068 - 7729 (2020) DOI: https://doi.org/10.14505/jemt 2020. C. 692-704

7. Yu. Becker, Spectroscopy (Moscow, Technosphere, 2009)

8. T.P. Stasenya, O.G. Mandrik, D.A. Yasnev, Working with arrays. analysis of sorting methods, Materials of reports of the 51st International Scientific and Technical Conference of Teachers and Students. Collection of scientific materials, 2 (2018)

9. V.Ya. Tsvetkov, Educational resources and technologies (2016)

10. Yu.B. Chetyrkin, E.M. Basarygina, V.V. Hiller, T.A. Putilova, Scientific analytical review, Chelyabinsk ( 2009)

11. V. Schmidt, Optical spectroscopy for chemists and biologists (Moscow, Technosphere, 2007) 